\title{
Design Analysis and performance evaluation of 3D printed baffle path diverters in hydraulic noise suppressor
}

\author{
Sumit Jadhav * and D. M. Mate", \\ * Department Mechanical Engineering, JSPM'S Rajarshi Shahu College of Engineering Pune \\ "PG Design Engg. Student, JSPM'S Rajarshi Shahu College of Engineering Pune
}

(Received 11 December 2020; Accepted 27 July 2021)

DOI: https://doi.org/10.36224/ijes.140305

\begin{abstract}
The pump in the hydraulic systems is the main source of noise in form of vibrations or pulsations while noise reduction is an important part of pump design still some ripples are produced by the pump termed as pulsations. Pulsations result in line vibrations which cause additional noise. How much ripple the pump produces cannot be changed, so other ways to an average of $50 \mathrm{~dB}(\mathrm{~A})$ to $60 \mathrm{~dB}(\mathrm{~A})$ level of noise is often considered to safe, although the noise levels resulting due to pulsations are seen to be in ranges as high as $130 \mathrm{t} 0150 \mathrm{~dB}(\mathrm{~A})$ that result in hose and piping failures and also results in damage to components like seals and valves. Through the introduction of a compressible membrane in the path with additional baffles for muffling of the noise the proposed solution is in the form of hydraulic noise reducer that incorporates both the compressible membrane as well as the baffle path diverter. Objective of paper is carried out the performance evaluation of the hydraulic noise reducer with elastomer membrane for noise reduction mechanism in conjunction to baffle type path diverters to even out the fluid pulsations or ripple to minimal without much pressure drop across the device to achieve minim; pumping losses. The paper discusses the performance evaluation of the diverter. The has been tested to determine mass flow rate and pressure drop. Experimental has been manufactured and test has been conducted to evaluate reduction in noiselevelinwithandwithoutthe3-dprintedbaffle arrangement and comparison has been carried out.
\end{abstract}

Keywords: hydraulic noise reducer, baffle path diverter

\section{Introduction}

Pressure on pump \& pump sizes having equal effects on hydraulic noise levels. Pump speed have about $300 \%$ greater effects on pump noise than either pressure or pump size. That is the reason too; some pump manufacturers recommend slower electric motor speeds. Fixed pumps are quieter to that of variable displacement pumps. It is impossible to forecast how much additional sound the hydraulic lines and surrounding structure will radiate.

Over the past years, nitrogen-charged accumulators have been installed in many hydraulic circuits to absorb pulsations. the first, accumulators were used as appendage devices - teed off the hydraulic line. Designer hoped that the pulsations would wander into the accumulator. However, experience showed that the majority of the pulsations bypassed the line leading to the accumulator. Different designs have been evolved in which the full flow was diverted into the accumulator. Correctly sizing this type of accumulator is complicated and the circuit that directs flow into the accumulator is very expensive. Also, the pressure drop through these accumulators may be unacceptably high. 


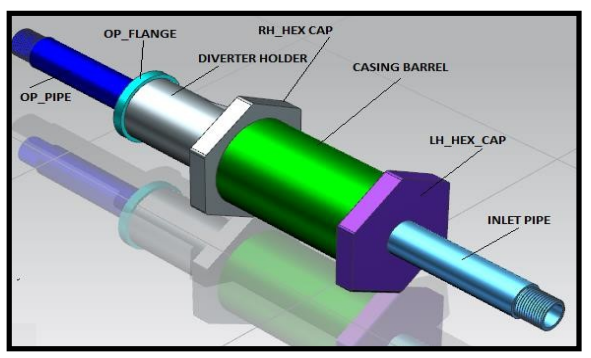

Figure 1: Construction of hydraulic noise reducer

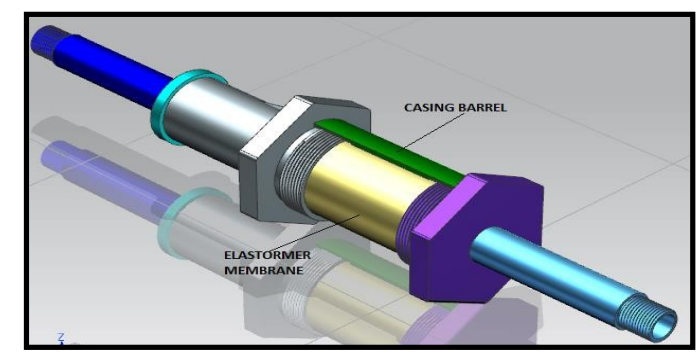

Figure.2: Elastomer membrane is installed in the casing barrel

The inlet pipe connects the output from the pump to the hydraulic actuator input. It is thread fitted in to the casing pipe. The baffle 3-d printed base that holds the baffles in place and diverts pulsating input from the pump into the muffling or diffuser chamber. Suppressor tube holds inlet muffler tube and outer muffler tube Inlet muffler tube is also called the diffuser tube (b). The tube is made of SS 304 material. The outer muffler tube is provided with holes, racially in a row and columns. The purpose of the holes is to allow the pulsating flow of oil from outlet to the resonator membrane or air bladder thereby diverting the path of oil the third time, thereby straightening of the flow pattern and reducing pulsations. When the pump is started the pulsating oil enters the resonator chamber and the flow is diverted by the three resonators that reduce the pulsations and the oil enters the inner diffuser tube. The oil is then channeled through the holes in the inner diffuser tube to the outer diffuser tube and then from the outer diffuser tube to the outlet. While the oil is moving the path of oil is diverted twice leading to flow straightening and reduction in the pulsations. The oil that moves out to the bladder strikes it where maximum energy of pulsation (noise) is absorbed and then the oil is again diverted from out diffuser holes to the inner diffuser holes and thereby the output at reduced noise and vibration.

The figure above shows how the elastomer membrane is installed in the casing barrel, this elastomer membrane encapsulates the inner perforated muffler and the elastic nature of the elastomer membrane helps the noise reduction through pulsations damping.

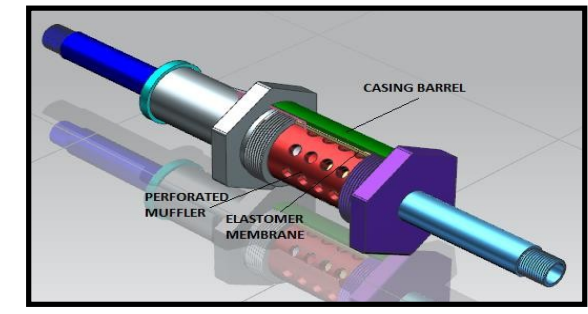

Figure 3: Perforated muffler



Figure 4: 3-D printed diverter

The fluid passages created by the baffle paths ensure the cancellation of the pulsations in the fluid by virtue of thorough intermixing of the particles.

\section{Design}

The design should consist of application of scientific principles, technical information and imagination for the development of new or improvised machine or mechanism to perform a specific function with maximum economy \& efficiency. Hence a careful design approach has to be adopted. The total design work, have been split up into two parts: 
1. System design

2. Mechanical Design

The System design mainly concerns the various physical constraints and ergonomics, space requirements, arrangement of various components on main frame at system, man + machine interactions, No. of controls, position of controls, working environment of machine, chances of failure, safety measures to be provided, servicing aids, ease of maintenance, scope of improvement, weight of machine from ground level, total weight of machine and a lot more.

In mechanical design the components are listed down and stored on the basis of their procurement, design in two categories namely:

1. Designed Parts

2. Parts to be purchased

For designed parts detached design is done \& distinctions thus obtained are compared to next highest dimensions which are readily available in market. This amplifies the Assembly as well as postproduction servicing work. The various tolerances on the works are specified. The process charts are prepared and phased on to the manufacturing stage.

The parts which are to be purchased directly are selected from the various catalogues \& specified so that anybody can purchase the same from the retail shop with given specifications.

\section{Components of the system}

\subsection{Inlet pipe}

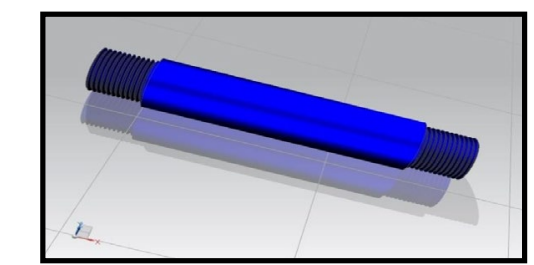

Figure 5(a): 3D model of Inlet pipe

\subsection{LH_hex_CAP}

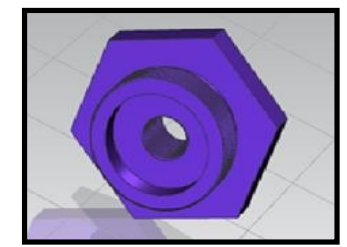

Figure 5(b): 3D model of LH_hex_CAP

\subsection{Casing Barrel}

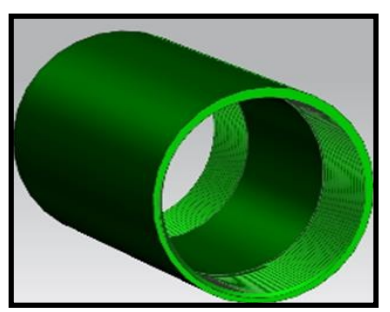

Figure 5(c): 3D model of Casing Barrel 
3.4.3-D printed Baffle path diverter

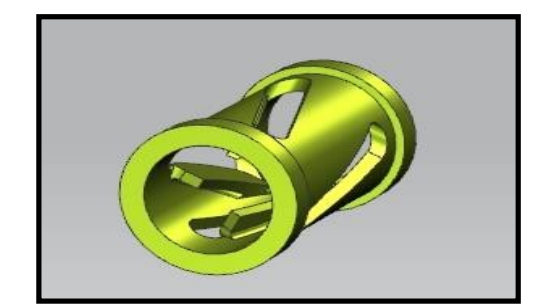

Figure 5(d): 3D model of 3-D printed Baffle path diverter

\section{5.liner holder}

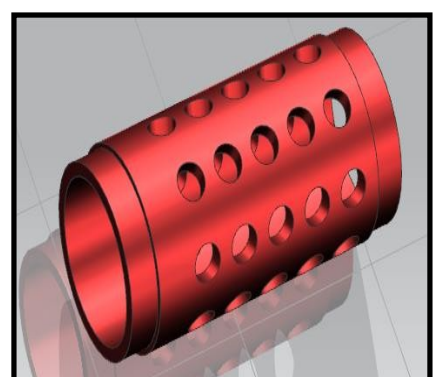

Figure 5(e): 3D model of liner holder

\section{Numerical Analysis}

The procedure of Static structural analysis using ANSYS Workbench is deliberated below:

1. Define the Material properties

2. Design the model

3. Import of Solid Model in ANSYS workbench \& Mesh Generation of Solid model

4. Apply the Boundary conditions and loading conditions.

5. Solving the analysis.

6. Generation of desired results.

The mesh model, \& apply boundary conditions for the results of analysis of different parts are given below:

\subsection{Analysis of Inletpipe}

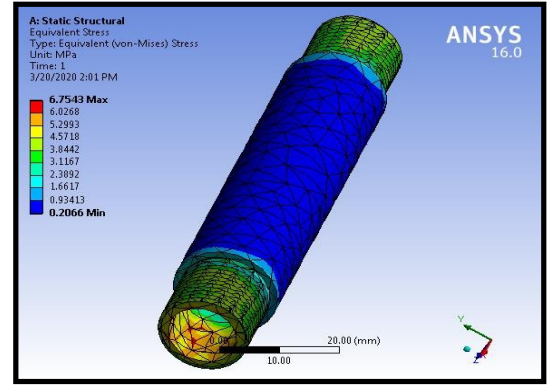

Figure 6: Von-misses stress of Inlet pipe

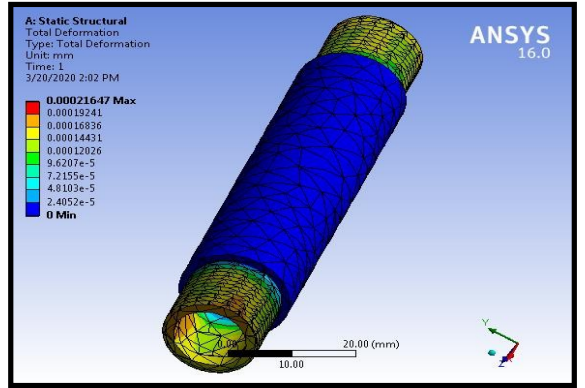

Figure 7: The maximum deformation of Inlet pipe 


\subsection{Analysis of LH_hex_CAP}



Figure 8: Von-misses stress of LH_hex_CAP

\subsection{Analysis of Casing Barrel}

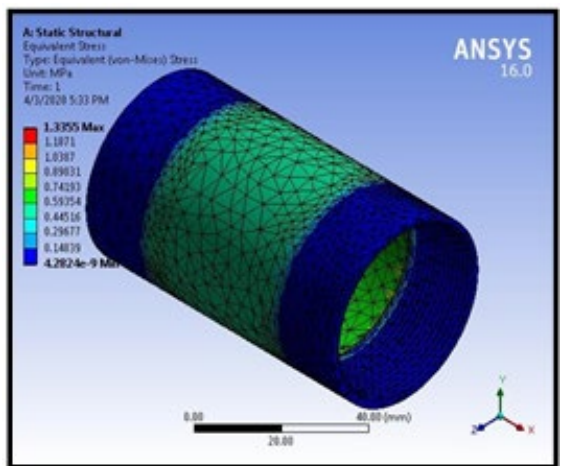

Figure 10: Von-misses stress of Casing Barrel

\subsection{Analysis of 3-D printed Baffle path diverter}

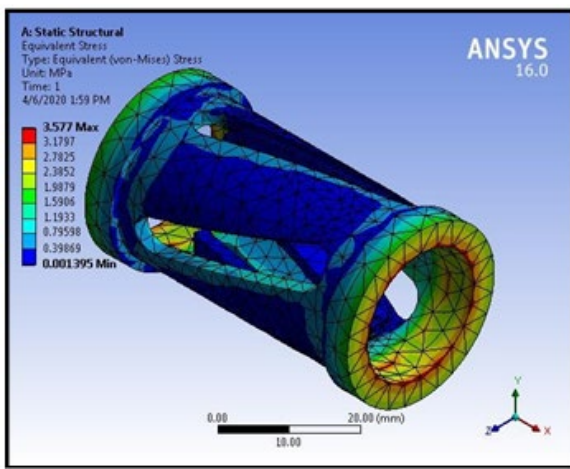

Figure 12: Von-misses stress of 3-D printed Baffle path diverter.

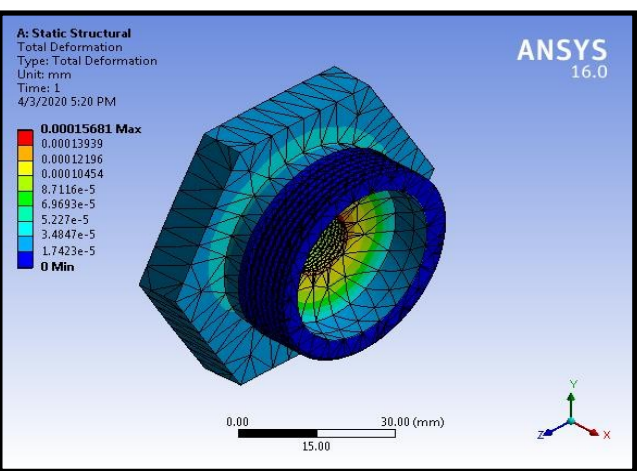

Figure 9: The maximum deformation of LH_hex_CAP

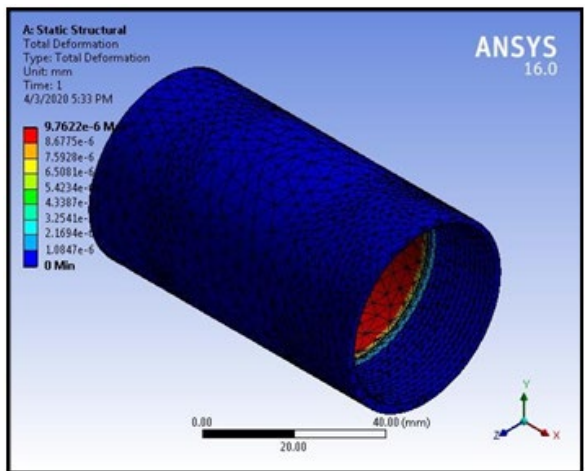

Figure 11: The maximum deformation of Casing Barrel

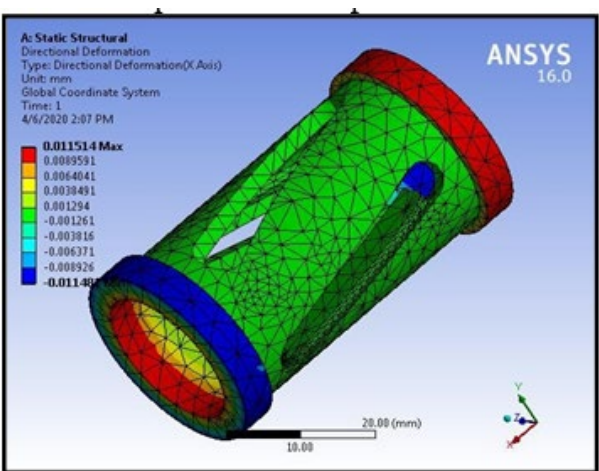

Figure 13: The maximum deformation of 3-D printed Baffle path diverter 


\subsection{Analysis of liner holder}



Figure 14: Von-misses stress of liner holder



Figure 15: The maximum deformation of liner holder

\section{Results of Analysis}

Table 1

\begin{tabular}{|l|l|l|}
\hline Components & Von- missesstress (Mpa) & Maximum deformation (mm) \\
\hline Inlet pipe & 4.725 & 0.0000216 \\
\hline LH_hex_CAP & 2.529 & 0.000165 \\
\hline Casing Barrel & 3.33 & $9.7 \mathrm{e}-6$ \\
\hline Baffle path diverter & 3.57 & 0.011514 \\
\hline liner holder & 1.1295 & $2.4202-5$ \\
\hline
\end{tabular}

\section{Testing \& trial of radial mounted 3-d printed baffle path diverters in hydraulic noise reducer.}

\subsection{Objectives of testing:}

Testing of the hydraulic noise suppressor for following characteristics
a) Drop in Pressure drop after diverter.
b) Noise level (dBA) without diverter.
c) Noise level (dBA) with diverter.
d) Comparison of noise levels.

\subsection{Procedure of trial}

1. First start the pump

2. Control the oil flow rate and set it at predetermined value using flow control valve.

3. Make note of pressure at inlet

4. Make note of pressure at outlet

5. Make note of e noise level

\section{Results}

Readings \& Observations

7.1. Test and trial on hydraulic noise reducer withoutthe diverter 
Table 2

\begin{tabular}{|l|l|l|l|l|l|}
\hline $\begin{array}{l}\text { Sr. } \\
\text { no. }\end{array}$ & Flow & $\begin{array}{l}\text { Inlet } \\
\text { Pressure } \\
\text { Bar }\end{array}$ & $\begin{array}{l}\text { Outlet } \\
\text { pressure } \\
\text { Bar }\end{array}$ & $\begin{array}{l}\text { Pressure } \\
\text { drop }(\Delta \mathrm{P})\end{array}$ & $\begin{array}{l}\text { Noised } \\
\mathrm{B}\end{array}$ \\
\hline 1 & 0.1 & 3.5 & 3.08 & 0.42 & 106.4 \\
\hline 2 & 0.2 & 3.5 & 3.12 & 0.38 & 107.2 \\
\hline 3 & 0.3 & 3.5 & 3.16 & 0.34 & 108.3 \\
\hline 4 & 0.4 & 3.5 & 3.19 & 0.31 & 109.6 \\
\hline 5 & 0.5 & 3.5 & 3.23 & 0.27 & 110.2 \\
\hline 6 & 0.6 & 3.5 & 3.24 & 0.26 & 110.8 \\
\hline 7 & 0.7 & 3.5 & 3.26 & 0.27 & 111.4 \\
\hline
\end{tabular}

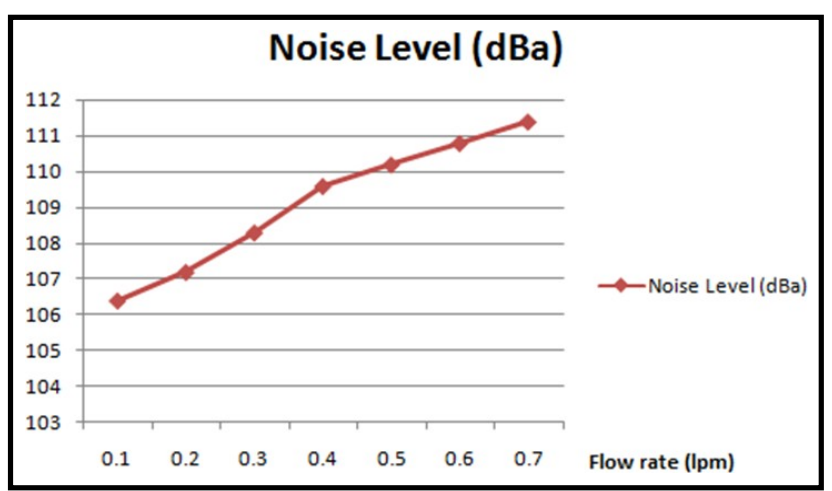

Graph 1: Noise Level Vs Flow rate

7.2. Test and trial on hydraulic noise reducer with the diverter

Table 3

\begin{tabular}{|l|l|l|l|l|l|}
\hline $\begin{array}{l}\text { Sr. } \\
\text { no. }\end{array}$ & Flow & $\begin{array}{l}\text { Inlet } \\
\text { Pressure } \\
\text { Bar }\end{array}$ & $\begin{array}{l}\text { Outlet } \\
\text { pressure } \\
\text { Bar }\end{array}$ & $\begin{array}{l}\text { Pressure } \\
\text { drop } \\
(\Delta \mathrm{P})\end{array}$ & $\begin{array}{l}\text { Noise } \\
\mathrm{dB}\end{array}$ \\
\hline 1 & 0.1 & 3.5 & 3.22 & 0.28 & 96.8 \\
\hline 2 & 0.2 & 3.5 & 3.26 & 0.24 & 96.2 \\
\hline 3 & 0.3 & 3.5 & 3.30 & 0.2 & 95.7 \\
\hline 4 & 0.4 & 3.5 & 3.33 & 0.17 & 95.1 \\
\hline 5 & 0.5 & 3.5 & 3.35 & 0.15 & 94.8 \\
\hline 6 & 0.6 & 3.5 & 3.37 & 0.13 & 94.3 \\
\hline 7 & 0.7 & 3.5 & 3.39 & 0.11 & 93.8
\end{tabular}

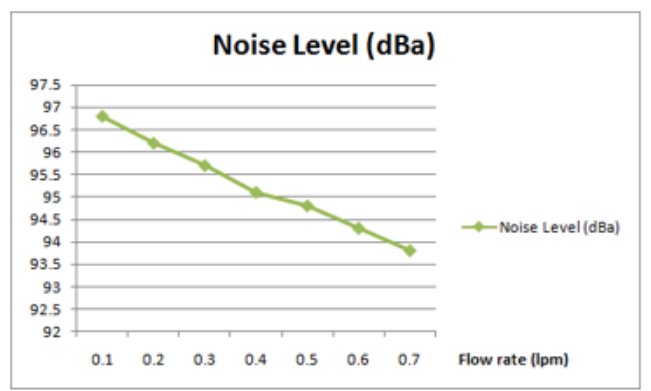

Graph 2: Noise Level Vs Flow rate 


\subsection{Comparison Graph of Noise Level Vs Flow rate}

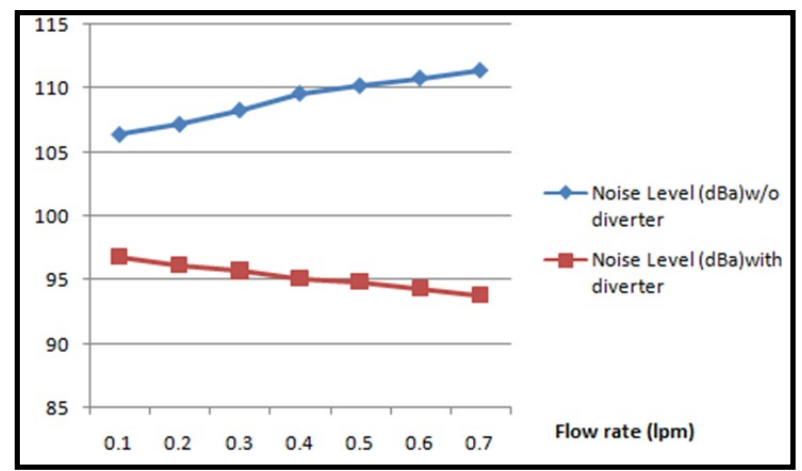

Graph3: Noise Level Vs Flow rate with and without diverter

\section{Result and discussion}

1. The outlet pressure is seen to increase in flow rate without diverter.

2. The pressure drop is seen to fall with the flow rate although very marginally as the maximum pressure drop is 0.42 at maximum flow rate which accounts to 12 percent of the inlet pressure without diverter

3. The noise level is observed to rise with the flow rate, maximum noise level is 111.4 which is less than the permissible noise level of the conventional system of $125 \mathrm{dBA}$ but still close to the permissible limit without diverter,

4. The outlet pressure is seen to increase in flow rate but marginally with diverter.

5. The pressure drop is seen to fall with the flowrate although very marginally as the maximum pressure drop is 0.28 at maximum flow rate which accounts to 8 percent of the inlet pressure with diverter.

6. The noise level is observed to rise with the flow rate, maximum noise level is 96.8 which is less than the permissible noise level of the conventional system of $125 \mathrm{dBA}$ but also it is far less than the permissible limit making the system safer.

7. The design and Analysis of parts indicates that all the parts are safe under given system of loads and the maximum von-misses stresses using Ansys Analysis are also well below the permissible limit of stress for the said parts thereby validating the design of parts.

\section{Conclusion}

Design analysis critical components of radial mounted 3-D printed baffle path diverters in hydraulic noise reducer are successfully done and the dimensions of the components have been determined. Estimation of the maximum stress induced in the components of the system have been determined by both theoretical method as well as using Ansys Work bench and the results indicate that the maximum stress values are well below the permissible limit hence the parts are safe under given system of loads.

The outlet pressure is seen to increase in flow rate in both cases but the outlet pressure is higher with the diverter added indicating good performance as there is better pressure output. The pressure drop is seen to fall with the flow rate although very marginally as the maximum pressure drop is 0.28 with the diverter at maximum flow rate which accounts to 8 percent of the inlet pressure whereas pressure dropis 0.42 at maximum flow rate which accounts to 12 percent of the inlet pressure.

The noise level is observed to rise with the flow rate, maximum noise level with diverter is 96.8 which is less than the permissible noise level of the conventional system of $125 \mathrm{dBA}$ but also it is far 
less than the permissible limit making the system safer as compared to without diverter maximum noise level is 111.4 which is less than the permissible noise level of the conventional system of $125 \mathrm{dBA}$ but still close to the permissible limit.

Thus, it can be concluded that with the introduction of the diverter using radial mounted 3-d printed baffle path the pressure drop is reduced, pressure output is increased, and the noise level is considerably reduced making the design safe and applicable.

\section{Acknowledgement}

I acknowledge and expressing my sincere thanks to my guide, Prof. Dr D.M.Mate his valuable suggestions, co-operation and continuous guidance.

I am very thankful to all the faculty members being a source of inspiration during the experimentation.

\section{References}

[1] Greg, Hayes, jeffLemond,katsuhikoOgata, Reducing Noise in Hydraulic System University Of Minnesota USA2004.

[2] Haruhiko kurino1, Yoshinori matsunaga2, Toshikazu yamada3 and jun tagami2 high performance passive hydraulic damper with semi-active characteristics Kajima Corporation, Tokyo, Japan. Email: kurino@kajima.com Vancouver, B.C., Canada2004

[3] S. Ramamoorthy, K. Grosh, J.M. Dodson, A theoretical study of structural acoustic silencers for hydraulic systems, Journal of the Acoustical Society of Americ.

[4] Sripriya Ramamoorthy and Karl Groshb "A theoretical study of structural acoustic silencers for hydraulic systemsa", University of Michigan, Ann Arbor, Michigan 48109-2125 February2002.

[5] K.A. Marek," Model and analysis of a cylindrical in-line hydraulic suppressor with a solid compressible liner, " Journal of Sound and Vibration 333 Atlanta, USA, August2014

[6] Ming-Hsiang Shih 1, Wen-Pei Sung 2, Cheer Germ Go 3 development of accumulated semi- active hydraulic dampers 3Professor, Dept. of Civil Engineering, National Chung-Hsing University, Taichung,TAIWAN.

[7] Harald Ortwig ''Experimental and analytical vibration analysis in fluid power systems'” International Journal of Solids and Structures 42 Trier University of Applied Sciences, Germany 2005 